\title{
Differences Among Influencing Factors of China's Provincial Energy Intensity: Empirical Analysis from a Geographically Weighted Regression Model
}

\author{
Jingmin Wang ${ }^{1}$, Keke Chen ${ }^{1,2 *}$, Xiaojing Song, ${ }^{1,2}$ \\ ${ }^{1}$ Department of Economics and Management, North China Electric Power University, Baoding, China \\ ${ }^{2}$ Beijing Key Laboratory of New Energy and Low-Carbon Development (North China Electric Power University), \\ Changping, Beijing, China
}

Received: 7 July 2019

Accepted: 15 October 2019

\begin{abstract}
China has the highest level of energy consumption in the world with comparatively low-level energy efficiency. Moreover, energy intensity varies greatly in the different provinces. It is necessary to find out the differences of influencing factors in various provinces in order to improve energy utilization while reducing the energy efficiency lags. Based on the panel data from 1995-2017, this paper investigates the driving factors of energy intensity through the spatial Durbin model. Then, in consideration of the inconsistency of the explanatory variables in different regions, the GWR model was established. The empirical results show that six factors have different impacts on local and surrounding areas in general. And the impact of six factors changed in research years as it was shown to be very different through the spatial distribution map. 30 provinces were finally divided into 7 groups according to various key impacts. Consequently, the government should take the differences of impacts in various provinces into account to formulate policies in reducing energy intensity.
\end{abstract}

Keywords: energy intensity, spatial heterogeneity, spatial Durbin model, geographically weighted regression model

\section{Introduction}

Energy is a basic guarantee for human activity and social development. Human activities consume fossil fuel energy and generate a large amount of greenhouse gases, such as carbon dioxide, that absorb surface radiation, resulting in a global greenhouse effect. According to global energy and $\mathrm{CO}_{2}$ status report, global energy-related $\mathrm{CO}_{2}$ emissions rose by $1.4 \%$ in 2017, leading to the global warming phenomenon becoming more and more serious. The current global average temperature increased by nearly $1^{\circ} \mathrm{C}$ above pre-industrial levels. Continued rising temperatures will not only lead to sea level rise and extreme weather, but also lead to a decline of crop yields, hindering the economic development of countries. The IPCC report on global warming highlighted the goals set out in the Paris Agreement, that the global ground and ocean surface average temperature must rise to within $1.5^{\circ} \mathrm{C}$. Under the severe background of the US withdrawal from the Paris Agreement, the agreed countries must 
control energy consumption in order to reduce carbon emissions on a large scale.

However, the growth rate of energy demand has increased while the world primary energy reserves are decreasing. In 2017, global primary energy consumption was raised by $2.2 \%$, mainly due to the increase in natural gas consumption. China is a major energy consumer mainly relying on coal [1]. The growth rate of energy consumption in China has ranked first in the world since 2010. Although coal consumption in China has declined slightly in recent years, it also accounts for a larger proportion. In 2017, coal accounted for $60.4 \%$ of primary energy consumption, decreasing slightly from 2016, which was still at a high level in the world. The use of fossil fuels has brought $\mathrm{PM}_{25}$ and ozone pollution, which has become a major threat to human life. Therefore, it is urgent to control energy consumption from the source. China is currently in a period of steady economic development with a mediumhigh level economic growth rate. However, energy efficiency in China is still at a low level and total energy consumption will continue to increase. How to control the speed of energy growth and reduce the dependence on energy consumption while growing economically is worth studying.

Energy intensity is an important indicator for evaluating energy efficiency in regional economic development, which can reflect regional energy conservation levels. China attaches great importance to the level of energy utilization and proposes to cut $15 \%$ energy intensity by 2020 . Many researchers have proven that due to resource endowments, economic levels and energy use levels are inconsistent in different provinces of China, and energy intensity varies greatly from region to region [2]. The economic development of oiland coal-rich areas in the central and western regions is not fast, and they are more dependent on energy consumption. On the contrary, economic development is faster in eastern regions with less of an energy supply. Consequently, the energy intensity in western regions is higher than that in the eastern region [3]. As the interaction between China's provinces becomes more frequent, the heterogeneity and spatial interaction between provinces must be considered when analyzing the method to reduce energy intensity. In recent years, energy intensity has declined in China, but some provinces have failed to meet energy-saving targets. At the end of the $13^{\text {th }}$ Five-Year Plan, finding out the influencing factors of energy intensity and studying the differences of influencing factors in various provinces will help to improve national energy efficiency while reducing the gap in energy utilization.

Analyzing the factors affecting energy intensity is necessary for the formulation and implementation of energy-saving policies. Researchers have systematically studied the influencing factors of energy intensity by different models, such as input-output, LMDI, STIRPAT and so on [4-5]. The input-output model seems to be popular in the industrial field. Li et al. proved that industrial transfer between cities played a critical role in energy intensity reduction by developing a multi-regional input-output model [6]. Lam et al. performed an environmentally extended input-output model for energy intensity of industry sectors analysis in Australia from 2006 to 2015 [7]. The spatial panel econometric model is a common method in energy intensity research recently. Zhang et al. confirmed the need to decompose energy intensity targets based on panel data from 30 Chinese provinces using three types of convergence model [8]. Zhang identified the causal relationship between energy intensity targets and wind energy generation capacities based on panel data of Chinese provinces from 2001 to 2014. The findings showed that the mandatory energy intensity targets are notably useful [9]. Nahla used panel autoregressive distributed lag approaches affirming that trade openness plays a key role in diminishing energy intensity [10].

As for results of these models, economic activity is considered to affect energy intensity generally. Scholars have approved of population as a great factor, including population size and urbanization rate, and energy use will increase with higher population size and urbanization rate. Yang et al. identified the total population as the most important factor affecting the energy intensity through the Pareto optimal model [11]. Economics has also been proven to be an important factor. Dong et al. found that economic structure and urbanization rate are the deterministic factors increasing energy intensity [12]. Soni et al. found that labor intensity has a positive impact on energy intensity - especially on low-energy intensity groups [13]. Petrović considered that energy intensity relating to the positive influence of industrial gross value be added [14]. Tan et al. found technology improvement effect is the most significant factor [15].

Many researchers have analyzed the impact of foreign investment and technology, and believe that foreign investment may improve technology, but its spillover effect will inhibit the reduction of energy intensity. Bu et al. [16], Jiang et al. [17] and Zhao [18] proved that foreign direct investment is an effective means to reduce energy intensity. But Huang et al. [19], Chen et al. [20] and other researchers have indicated that indigenous innovations play a more important effect on energy intensity than foreign innovations [21]. Price confirms the effect of energy in previous studies. Amin Karimu et al. found that input prices were significant determinants of energy intensity [22], while Verbič regarded electricity prices as a potential energy policy tool for reducing energy intensity [23]. Besides, some researchers have studied the effects of energy intensity on other aspects. Guo et al. reveals that optimizing energy structure may be the best way to reduce energy intensity in the short run [24]. Nielsen presented that the efficiency in expanding the electricity system accounted for energy intensity [25].

However, few studies consider the heterogeneity between provinces. The realistic influence of factors 
is skewed due to the complexity and variability of socioeconomic development. Lin and Chen applied profit function into the input-output system using China's provincial data. The results indicate that economic infrastructure construction will reduce the energy intensity in the long term [26]. Guang et al. estimated a penalized panel quantile regression model that accounts for the different influences of economic growth, urbanization, foreign direct investment, energy structure, and industrialization across the regions of China [27]. But most researchers did not consider the impact of geographic heterogeneity on models. The geographically weighted regression (GWR) model embeds spatial location into the regression parameter and reflects the spatial non-stationary nature of the parameters in different regions, which promotes the relationships among the variables able to change with their spatial positions [28-29]. The GWR model was recently used in a study of air quality and carbon dioxide but less for energy intensity. Taking the impact of geographic heterogeneity into consideration, this paper use GWR to analyze the different influences of various factors in energy intensity.

This paper intends to analyze the influencing factors of energy intensity by the spatial Durbin model, which takes the influence of geographical lag into consideration, with a panel data of China's 30 provinces during the period 1995 to 2017. Then it uses the GWR model to find the differences of influencing factors in each province. This paper is composed of five sections, with the remaining sections as follows: Section 2 relates the econometric model establishment and the data description, Section 3 presents the estimation results, Section 4 implements an in-depth discussion on the spatial Durbin results and GWR results, and Conclusions and policy suggestions are placed in Section 5 .

\section{Experimental}

\section{Spatial Autocorrelation Test}

Spatial correlation is the interaction between research subjects in different geographical regions as determined by the space geographical relationship, rather than due to time or other external forces. The spatial autocorrelation test is a necessary step before spatial measurement analysis. Eq. (1) shows the calculation formula of Moran's I index that correlates the similarity of the values of a region's neighboring spaces to study global spatial correlation [30]:

$$
\begin{aligned}
I & =\frac{n \sum_{i=1}^{n} \sum_{j=1}^{n} w_{i j}\left(x_{i}-\bar{x}\right)\left(x_{j}-\bar{x}\right)}{\sum_{i=1}^{n} \sum_{j=1}^{n} w_{i j} \sum_{i=1}^{n}\left(x_{i}-\bar{x}\right)^{2}} \\
& =\frac{\sum_{i=1}^{n} \sum_{j=1}^{n} w_{i j}\left(x_{i}-\bar{x}\right)\left(x_{j}-\bar{x}\right)}{S^{2} \sum_{i=1}^{n} \sum_{j=1}^{n} w_{i j}}
\end{aligned}
$$

...where $x_{i}$ and $x_{j}$ represent the observed energy intensity values of provinces $i$ and $j$ respectively, $n$ is the number of research objects and $\mathrm{W}_{\mathrm{ij}}$ represents the spatial weight matrix. Moran's I index is generally between -1 and 1 , and a value greater than 0 indicates that there is an accumulation in the region.

The weight matrix is used for measuring the spatial location geographic relationship. The farther the geographical distance, the smaller the interaction relationship will be; the inverse distance matrix takes the reciprocal of the exponential power of the distance between two regions as the matrix element, and is expressed as Eq. (2):

$$
w_{i j}= \begin{cases}1 / d_{i j}^{\alpha} & i \neq j \\ 0 & i=j\end{cases}
$$

...where $\mathrm{d}$ is the distance between two provinces and $\alpha$ is the set power exponent.

Considering the relationship between objects in different regions and surrounding adjacent regions, local spatial autocorrelation can reflect not only the correlation between a certain area and the surrounding area, but also the heterogeneity of the entire space research object. Moran scatter plots and LISA are commonly used for local spatial autocorrelation analysis. The model results divide the provinces into four spatial correlations: HH, LH, LL and HL, indicating the results of different high- and low-value aggregations respectively.

\section{Spatial Durbin Model}

According to previous literature on energy intensity, factors such as economic level, social development, energy utilization, industrial development, technological progress and market opening have direct or indirect effects on the change of energy intensity. Different indicators change energy intensity by influencing total energy consumption or gross national product. In order to further analyze the influence of energy intensity on the different provinces, this paper is intended to choose the factors that have a greater impact and can be well controlled. Finally, 6 influential factors were selected as explanatory variables in the model.

Firstly, as a low calorific value energy, the use of coal has greatly increased energy consumption, and the proportion of coal consumption should be considered. Industrial structure is an important factor affecting coal consumption - especially energy- and carbonintensive enterprises according to China's authentic situation [31]. This paper takes secondary industry proportion into models. China is currently at the stage of rapid urbanization that not only leads to rapid expansion of urban population, but also results in the significant demand of energy use [32]. Urbanization rate is an important factor affecting energy intensity. The extension of freeways and new energy vehicles has also effectively reduced the proportion of oil consumption, 
thus the factor of civil vehicles is put in. Finally, technology and openness have different conclusions in previous studies, which are related to the actual conditions of different regions [33]. Therefore, the influencing factors like R\&D expenditure and foreign direct investment should be adopted in the model.

Consequently, a non-spatial panel data model (OLS) is established as Eq. (3):

$$
\begin{gathered}
\ln E I_{i t}=\alpha+\ln C V_{i t} \beta_{1}+\ln C R_{i t} \beta_{2}+\ln R D_{i t} \beta_{3} \\
+\ln U R_{i t} \beta_{4}+\ln F D I_{i t} \beta_{5}+\ln I S_{i t} \beta_{6} \\
+\mu_{i}+\eta_{t}+\varepsilon_{i t}
\end{gathered}
$$

...where $\operatorname{lnEI}, \ln C \mathrm{~V}, \operatorname{lnCR}, \ln \mathrm{RD}, \ln \mathrm{R}, \ln \mathrm{nDI}$ and $\ln I S$ represent possession of energy intensity, civil vehicles, proportion of coal consumption, $\mathrm{R} \& \mathrm{D}$ expenditure, urbanization rate, foreign direct investment and secondary industry proportion respectively. $\beta_{\mathrm{k}}$ is the coefficient of the k-th influence factor, $\mu_{\mathrm{i}}$ and $\eta_{\mathrm{t}}$ represent spatial and temporal effects, and $\varepsilon_{\mathrm{it}}$ stands for error term.

As the spatial heterogeneity and spatial correlations exist, energy intensity of a certain region is affected not only by the local environmental condition, but also by its neighboring region. The results coefficients of classical non-spatial panel assumptions will be biased and inconsistent. Therefore, the spatial econometric model is established to obtain accurate regression results. The inter-regional relationships are introduced into the spatial econometric model, which is mainly divided into the spatial cross-section model and the spatial panel model [33]. The spatial econometric model sets the location of the space item according to different variables of spatial correlation including the explained variables, error terms and explanatory variables, which are applied as spatial lag model (SLM), spatial error model (SEM) and spatial Dubin model (SDM) respectively.

The spatial Durbin model considers the endogenous and exogenous correlation between interpreted variables as well as explanatory variables into the model. Therefore, this paper conducted the SDM to examine the influence factors of energy intensity and its spillover effects. The model with 6 influence factors and the lag term of them can be expressed as Eq. (4).

$$
\begin{gathered}
\ln E I_{i t}=\rho W_{i} \ln E I_{i t}+\ln C V_{i t} \beta_{1}+\ln C R_{i t} \beta_{2} \\
+\ln R D_{i t} \beta_{3}+\ln U R_{i t} \beta_{4}+\ln F D I_{i t} \beta_{5}+\ln I S_{i t} \beta_{6} \\
+W_{i} \ln C V_{i t} \gamma_{1}+W_{i} \ln C R_{i t} \gamma_{2}+W_{i} \ln R D_{i t} \gamma_{3} \\
+W_{i} \ln U R_{i t} \gamma_{4}+W_{i} \ln F D I_{i t} \gamma_{5} \\
+W_{i} \ln I S_{i t} \gamma_{6}+\mu_{i}+\eta_{t}+\varepsilon_{i t}
\end{gathered}
$$

...where $\rho$ denotes the spatial autocorrelation coefficient, $\beta$ is the spatial regressive coefficients, $\gamma$ represent the spillover effects of variables, WlnEI is the spatial lag terms of energy intensity, WlnEI, WlnCV, WlnCR, WlnRD, WlnUR, WlnFDI and WlnIS respectively stand for the spatial lag terms of six independent variables, $\mu_{\mathrm{i}}$ and $\eta_{\mathrm{t}}$ represent spatial and temporal effects, and $\varepsilon_{\mathrm{it}}$ stands for error term.

\section{Geographically Weighted Regression Model}

The influence of different types of time effects and spatial effects on regional observation objects is considered in the spatial Durbin model, but the final results represent the average of the whole region, which ignored the inconsistency of the explanatory variables in different regions. Introducing the concept of variable parameters into the GWR model which effectively incorporates the heterogeneity of non-stationary space into the study, the variation of parameter estimates in different regions is analyzed from the local point of view to reflect the characteristics of the actual spatial distribution.

Taking the regional geographic location information and 6 selected influencing factors into the GWR model, the model can be expressed as Eq. (5).

$$
\begin{aligned}
\ln E I_{i}= & \beta_{0}\left(u_{i}, v_{i}\right)+\ln C V_{i} \beta_{1}\left(u_{i}, v_{i}\right)+\ln C R_{i} \beta_{2}\left(u_{i}, v_{i}\right) \\
& +\operatorname{lnR} D_{i} \beta_{3}\left(u_{i}, v_{i}\right)+\ln U R_{i} \beta_{4}\left(u_{i}, v_{i}\right) \\
& +\ln F D I_{i} \beta_{5}\left(u_{i}, v_{i}\right)+\ln I S_{i} \beta_{6}\left(u_{i}, v_{i}\right)+\varepsilon_{i}
\end{aligned}
$$

...where $\left(\mathrm{u}_{\mathrm{i}}, \mathrm{v}_{\mathrm{i}}\right)$ stands for the latitude and longitude position of the $\mathrm{i}$-th province, $\beta_{0}$ is an intercept term, $\beta_{\mathrm{k}}\left(\mathrm{u}_{\mathrm{i}}, \mathrm{v}_{\mathrm{i}}\right)$ is a function of location $\left(\mathrm{u}_{\mathrm{i}}, \mathrm{v}_{\mathrm{i}}\right)$ that indicates the parameter vector of $\mathrm{k}$-th factor in $\mathrm{i}$-th province to be estimated, and $\varepsilon_{\mathrm{it}}$ is a random error term.

The coefficients $\beta$ were estimated by the weighted least squares method as Eq. (6).

$$
\hat{\beta}_{i}=\left(X^{T} W_{i} X\right)^{-1} X^{T} W_{i} Y
$$

...where $\beta_{\mathrm{i}}$ represents estimate vector of region regression coefficient, and $\mathrm{W}_{\mathrm{i}}$ is the diagonal matrix of spatial weight function between the i-th region and the remaining regions

The spatial weight function $\mathrm{W}$, also known as the kernel function, is an important part of the geographically weighted regression model [35]. Considering that the spatial relationship decreases with increasing distance, this paper uses the Gaussian spatial weight function to optimize the fitting effect. Gaussian function takes the distance as a negative exponential power so that the weight will not become maximal when the distance is close. The formula is shown as Eq. (7):

$$
w_{i j}=\exp \left[-\left(\frac{d_{i j}}{h}\right)^{2}\right]
$$

...where $d_{i j}$ is the Euclidean distance between regions, $\mathrm{h}$ is the bandwidth, the larger $\mathrm{h}$ is, the slower the weight function value changes.

In order to accurately reflect the spatial nonstationarity of the region, an optimal bandwidth can be 
determined by AIC method, which avoids over-fitting and reducing the complexity of the model.

\section{Results and Discussions}

\section{Spatial Relationship Analysis}

\section{Spatial Heterogeneity}

Energy intensity of different provinces varies greatly. From the average data, Ningxia is the region with the highest energy intensity, reaching 4.41 tons of standard coal per 10,000 yuan in 1995-2017, which is 2.88 times of the national average energy intensity. The region with the lowest energy intensity is Fujian, and its average energy intensity is 0.83 tons of standard coal per 10,000 yuan.

As shown in Fig. 1, provinces are divided into four grades according to their energy intensity, which is generally high in the northwest and low in the southeast. Energy intensity of all provinces showed a decreasing trend, while the change of the energy intensity grades in provinces was different. In the period of 1995-2002, energy intensity grades for Xinjiang, Yunnan, and Hubei became higher, while Hunan and Chongqing became lower. Hebei and Guangxi had higher energy intensity grades, while Shanghai, Gansu, and Beijing were lower between 2002 and 2010. Energy intensity grades of Henan and Hainan became higher from 2010 to 2017 .

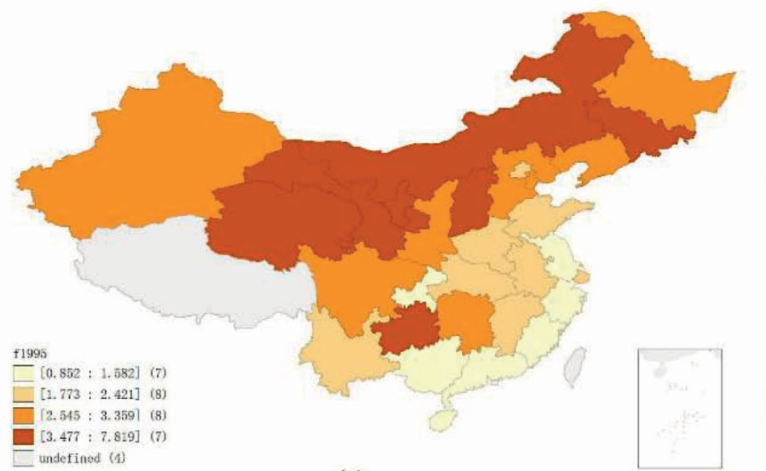

(a)

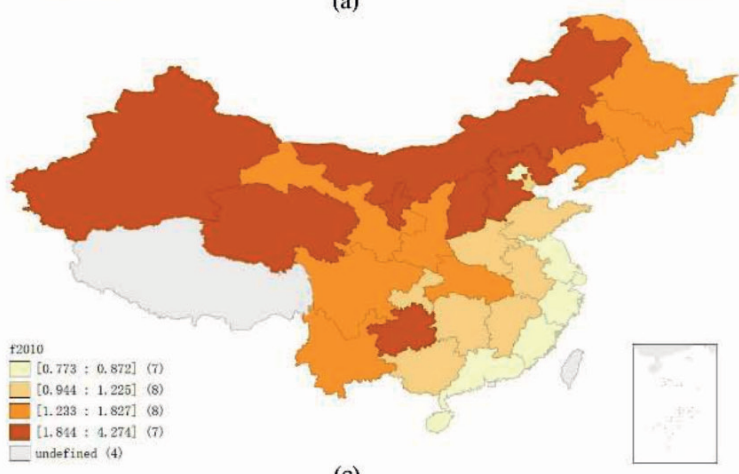

(c)

\section{Spatial Autocorrelation}

The energy intensity of China's provinces is affected by the nearby provinces, resulting in a certain aggregation effect. The results of Moran index from 1995 to 2017 was calculated respectively to analyze global autocorrelation. As shown in Table 1, the value of Moran's I is greater than 0 , and the $\mathrm{P}$ value is less than 0.05 in most years, indicating that China has passed the global autocorrelation significance test and the aggregation of energy intensity in China is significant. In recent years, the index is higher and more significant than before, which means that the autocorrelation effect is enhanced.

Carrying out local autocorrelation tests on the energy intensity of various provinces, and the Molan scatter plots in 1995, 2002, 2010 and 2017 were plotted respectively. As shown in Fig. 2, the distribution of most provinces in each year tends to be in the first and third quadrants, and the slope of the trend line is positive. Therefore, the energy intensity of each province passes the local autocorrelation test, which indicates that there is an aggregation phenomenon among the energy intensity of provinces. The number of provinces with high energy intensity aggregation and low value aggregation was similar at the first year in this research. But over time, the number of low-value aggregation provinces became larger, while the number of high-value clusters was greatly reduced. This shows that the high-value aggregation effect is weakened, and some provinces in high-energy intensity areas change to low-energy intensity regions.

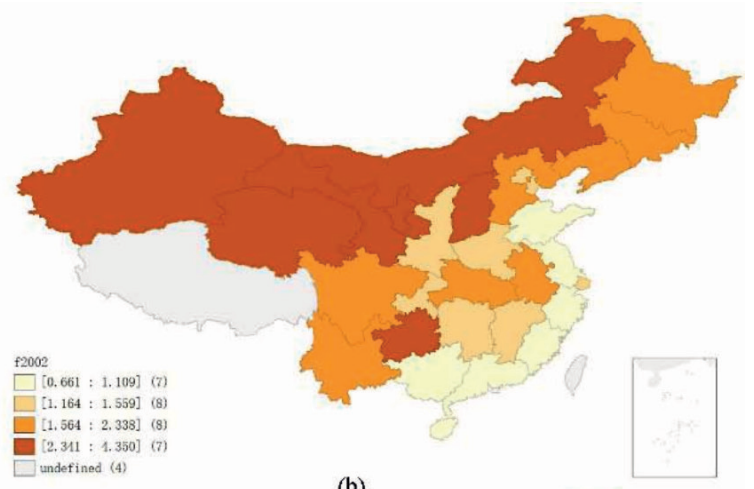

(b)

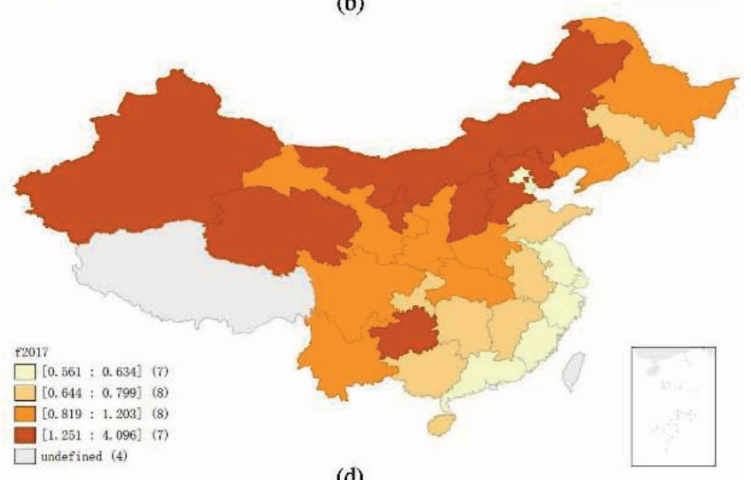

(d)

Fig. 1. Spatial distribution map of energy intensity in each province. 
Table 1. Moran index of China from 1995 to 2017.

\begin{tabular}{|c|c|c|c|c|c|c|c|c|c|}
\hline Year & Moran's I & $\mathrm{p}$ & $\mathrm{sd}$ & Z-value & Year & Moran's I & $\mathrm{p}$ & sd & Z-value \\
\hline 1995 & 0.1322 & 0.025 & 0.0720 & 2.3273 & 2007 & 0.1100 & 0.051 & 0.0756 & 1.9032 \\
\hline 1996 & 0.1413 & 0.031 & 0.0772 & 2.2887 & 2008 & 0.1196 & 0.041 & 0.0762 & 2.0132 \\
\hline 1997 & 0.1277 & 0.037 & 0.0763 & 2.1420 & 2009 & 0.1378 & 0.026 & 0.0764 & 2.2422 \\
\hline 1998 & 0.0783 & 0.068 & 0.0759 & 1.4984 & 2010 & 0.1386 & 0.033 & 0.0765 & 2.2518 \\
\hline 1999 & 0.0949 & 0.060 & 0.0775 & 1.6770 & 2011 & 0.1326 & 0.030 & 0.0752 & 2.2083 \\
\hline 2000 & 0.1155 & 0.052 & 0.0783 & 1.9147 & 2012 & 0.1399 & 0.027 & 0.0754 & 2.2962 \\
\hline 2001 & 0.1089 & 0.060 & 0.0777 & 1.8454 & 2013 & 0.1506 & 0.014 & 0.0755 & 2.5589 \\
\hline 2002 & 0.1044 & 0.064 & 0.0770 & 1.8084 & 2014 & 0.1587 & 0.016 & 0.0756 & 2.5307 \\
\hline 2003 & 0.0988 & 0.065 & 0.0758 & 1.7555 & 2015 & 0.1696 & 0.015 & 0.0749 & 2.7008 \\
\hline 2004 & 0.1025 & 0.058 & 0.0747 & 1.8283 & 2016 & 0.1557 & 0.018 & 0.0750 & 2.5169 \\
\hline 2005 & 0.1112 & 0.050 & 0.0748 & 1.9416 & 2017 & 0.1490 & 0.015 & 0.0728 & 2.5060 \\
\hline 2006 & 0.1029 & 0.058 & 0.0750 & 1.8272 & & & & & \\
\hline
\end{tabular}

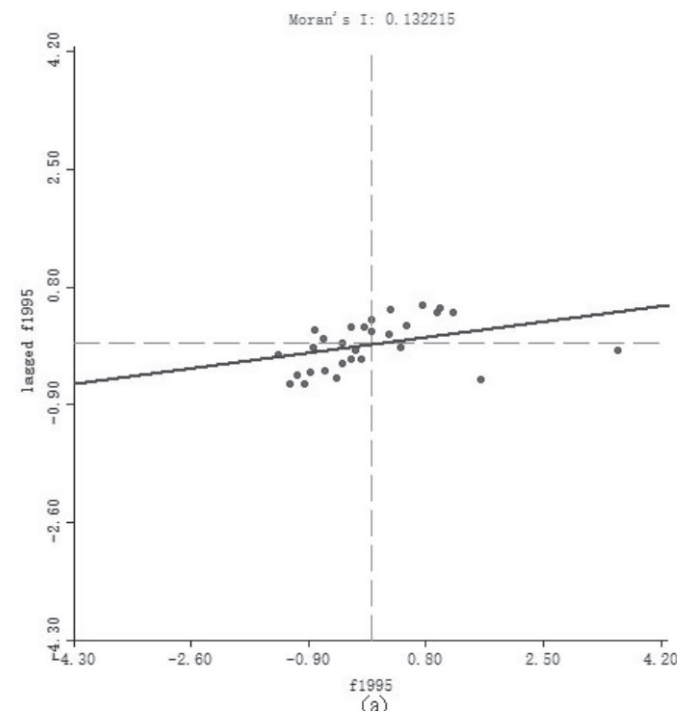

(a)

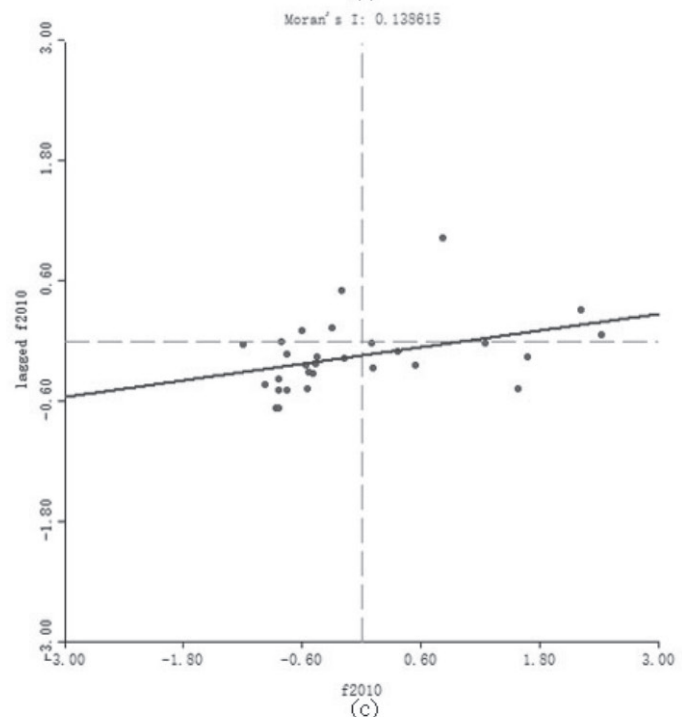

(c)

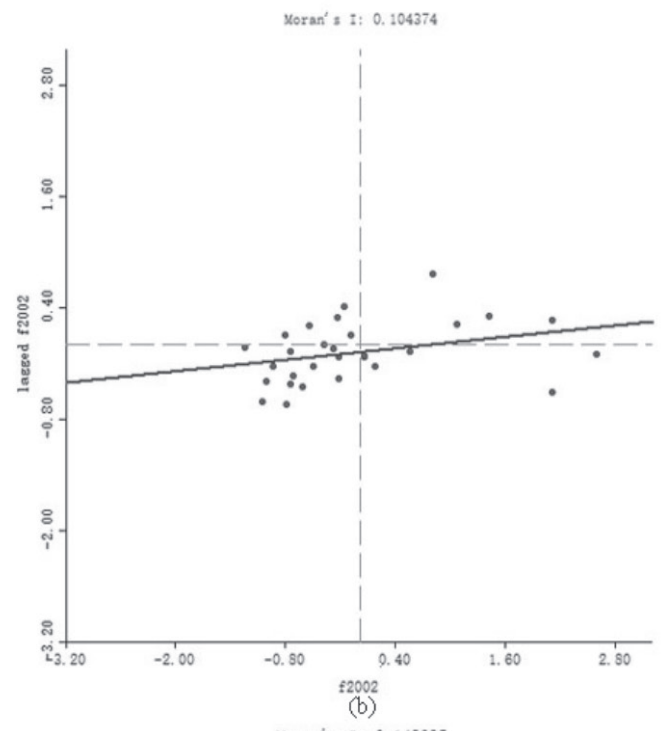

Xoran's I: 0.149035

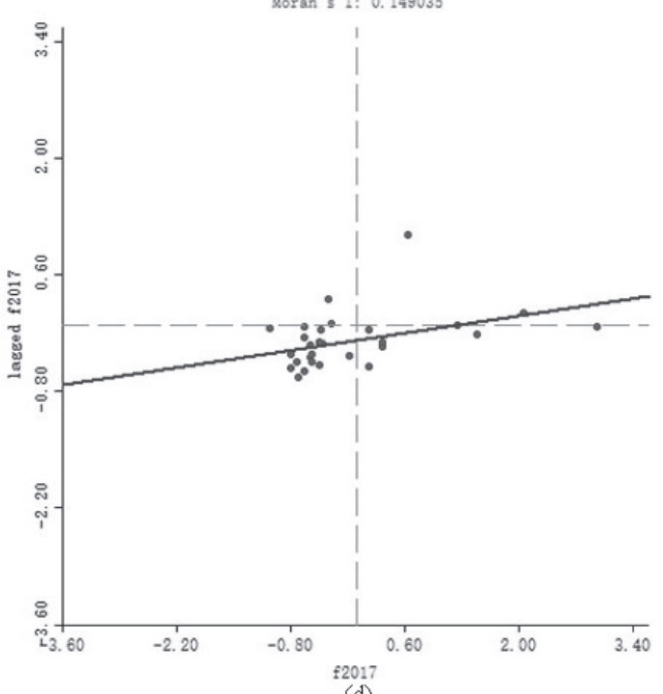

(d)

Fig. 2. Moran scatter plot. 


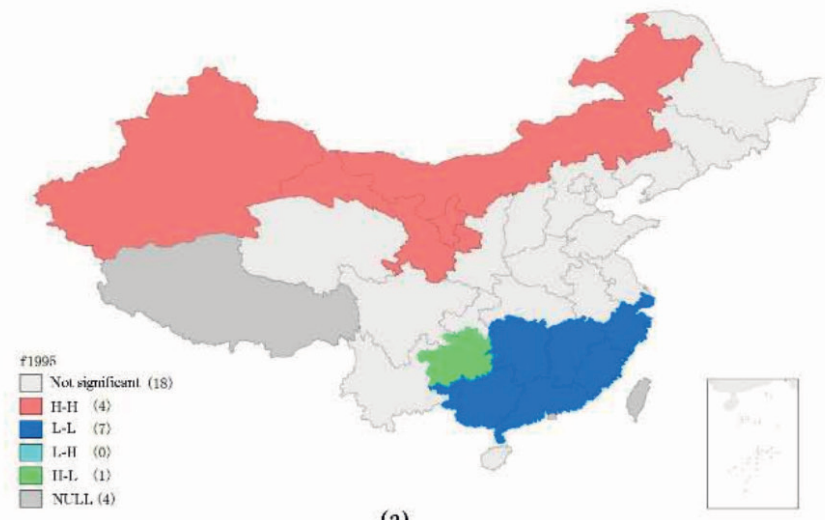

(a)

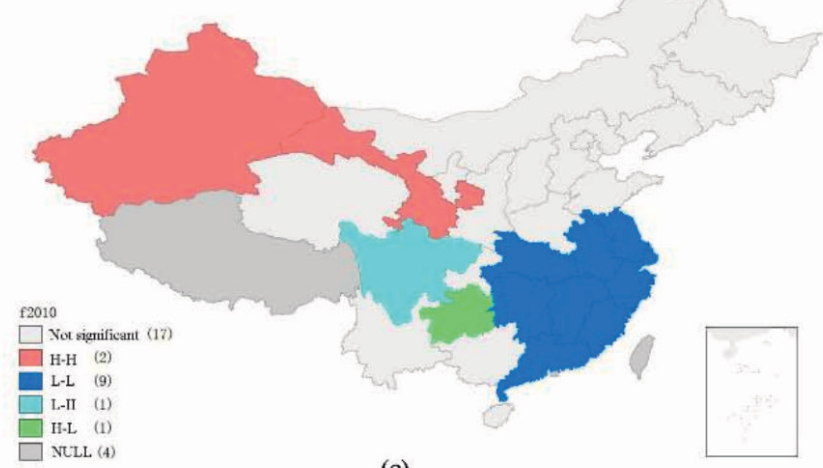

(c)

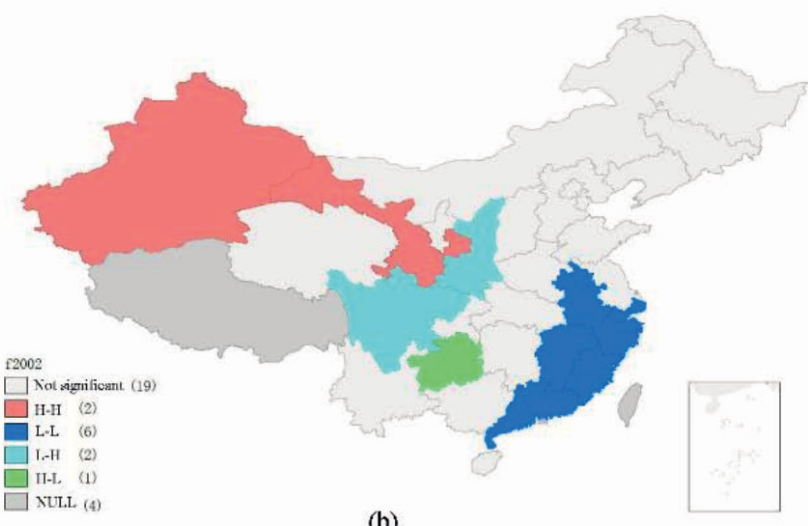

(b)

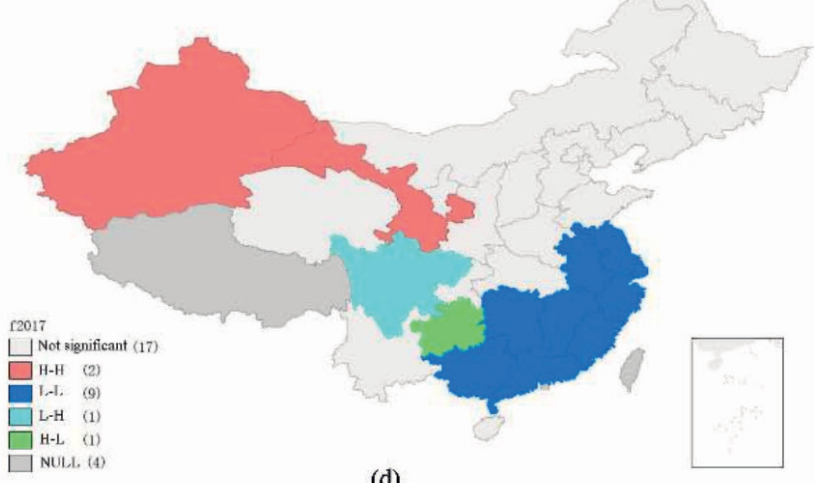

(d)

Fig. 3. Lisa aggregation map.

The Lisa aggregation map of the energy intensity of each province in 1995, 2002, 2010, and 2017 respectively are shown in Fig. 3, in order to show the locations of the aggregation phenomenon. At the level of significance of 0.1 , several provinces pass the correlation test, and the aggregation areas of one to four quadrants are basically distributed from northwest to southeast.

Xinjiang and Gansu have always been the highhigh energy intensity zones, forming the high-value aggregates in northwest China, but Ningxia and Neimenggu have not shown obvious aggregation except in 1995. Energy intensity in Sichuan has been shown as the low-high aggregation since 2002, and its energy intensity level is relatively low in southwest China. Guizhou has always been a high-low energy intensity zone, as it is located at the junction of the southeast low-intensity zones and the west high-intensity zones. The coastal areas have always been the low-low energy intensity zones, forming a southeast low-value cluster, and the scope has been expanded.

\section{Results of the Spatial Dubin Model}

The estimation results of the panel OLS model are shown in Table 2. The results of the residual LM test show that the error term and lag term pass the significance test, as their $\mathrm{P}$ value are less than 0.05 . Ward test and LR test results in Table 3 reject the original hypothesis at the $1 \%$ level, which indicate that the transformation from the spatial panel Durbin model to the spatial autocorrelation model or spatial lag model is not needed. Therefore, the spatial panel Doberman model can be used.

According to the results of the Hausman test, chisquare statistic is 71.9291 , and $p$ value is less than 0.01 ,

Table 2. Estimation results of the OLS model.

\begin{tabular}{|c|c|c|c|}
\hline Variable & Coefficient & t-statistic & p-value \\
\hline Intercept & -2.840422 & -10.205039 & 0.000000 \\
\hline LnCV & 0.069575 & 2.984685 & 0.002940 \\
\hline LnCR & 0.129924 & 5.443477 & 0.000000 \\
\hline LnRD & -0.103713 & -5.347702 & 0.000000 \\
\hline LnUR & 0.155588 & 3.816708 & 0.000148 \\
\hline LnFDI & -0.206649 & -19.414952 & 0.000000 \\
\hline LnIS & 0.729935 & 11.819401 & 0.000000 \\
\hline & $\mathrm{R}^{2}$ & \multicolumn{2}{|c|}{0.6967} \\
\hline Adj-R ${ }^{2}$ & \multicolumn{2}{|c|}{140.9382} \\
\hline Log-likelihood & \multicolumn{2}{|c|}{$99.7088, \mathrm{P}=0.000$} \\
\hline LM test no spatial lag & $142.9944, \mathrm{P}=0.000$ \\
\hline Robust LM test no spatial lag & \multicolumn{2}{|c|}{$58.9896, \mathrm{P}=0.000$} \\
\hline \multicolumn{2}{|c|}{ LM test no spatial error } & \multicolumn{2}{|c|}{} \\
\hline Robust LM test no spatial error & & \multicolumn{2}{|c|}{$5=0.000$} \\
\hline
\end{tabular}


Table 3. Results of ward test and LR test.

\begin{tabular}{|c|c|c|}
\hline Test & Statistic & p-value \\
\hline Wald_spatial_lag & 155.6516 & 0.000 \\
\hline Wald_spatial_error & 107.7777 & 0.000 \\
\hline LR_spatial_lag & 190.6135 & 0.000 \\
\hline LR_spatial_error & 166.8543 & 0.000 \\
\hline
\end{tabular}

so the fixed effect is more appropriate. Estimating 4 types of model including the random effect model, the spatial fixed effect model, the time fixed effect model, and the spatiotemporal dual fixed effect model, the results are shown in Table 4. Other spatial weight matrices are considered to test the robustness of the estimation results in order to avoid the arbitrariness of the impact of the spatial weight matrix choice on the SDM estimation results. The estimation results based on the four spatial weight matrices are consistent, which shows that the model estimation results have strong robustness. The spatiotemporal dual fixed effect model has the largest $\mathrm{R}^{2}$ and log-likelihood values, but the adjustment $\mathrm{R}^{2}$ is smaller. The spatial fixed effect model selected as the adjustment $\mathrm{R}^{2}$ is the largest, and the log-likelihood value is not much different from the spatiotemporal dual fixed effect model.
Different from the results in OLS estimation is that all the influencing factors passed the $1 \%$ significance level test, and the coefficient of civil vehicles failure passed the significance test in the spatial panel Dubin model. The coefficient of foreign direct investment is negative in both models, restraining local energy intensity. The proportion of coal consumption, urbanization rate and secondary industry proportion have a positive coefficient, which promotes the local energy intensity. The estimated coefficient of R\&D expenditure is negative in the OLS model, while it becomes positive in the spatial panel Dubin model.

The lag coefficient of energy intensity is positive through the $1 \%$ level significance test, which shows that energy intensity in the surrounding area has a positive effect on the local region. $R \& D$ expenditure has a negative lag coefficient, indicating that the surrounding R\&D expenditure is the disincentive to local energy intensity. Civil vehicles, urbanization rate and secondary industry proportion in the surrounding areas have contributed to the energy intensity of the local region, as the lag coefficients of these factors are positive. The lag coefficients of coal consumption proportion and foreign direct investment were not significant.

Considering the feedback effect of the energy intensity lag term in the spatial panel Dubin model,

Table 4. Fixed effect selection and estimation results of spatial Durbin model.

\begin{tabular}{|c|c|c|c|c|c|c|}
\hline Variable & Coefficient & t-statistic & $\mathrm{p}$-value & $\mathrm{W}_{2}$ & $\mathrm{~W}_{3}$ & $\mathrm{~W}_{4}$ \\
\hline $\mathrm{LnCV}$ & 0.026038 & 0.935332 & 0.349617 & 0.054470 & 0.012512 & 0.010491 \\
\hline LnCR & 0.043027 & 3.889932 & 0.000100 & 0.044227 & 0.058351 & 0.056217 \\
\hline LnRD & 0.065789 & 3.650728 & 0.000261 & 0.022994 & 0.043749 & 0.063759 \\
\hline LnUR & 0.121683 & 3.108087 & 0.001883 & 0.105013 & 0.147691 & 0.130604 \\
\hline LnFDI & -0.031690 & -3.681137 & 0.000232 & -0.01480 & -0.02355 & -0.03196 \\
\hline LnIS & 0.300241 & 6.451869 & 0.000000 & 0.313390 & 0.254131 & 0.245483 \\
\hline $\mathrm{W}^{*} \mathrm{LnCV}$ & 0.199485 & 3.490955 & 0.000481 & 0.022827 & 0.103903 & 0.006157 \\
\hline $\mathrm{W}^{*} \mathrm{LnCR}$ & -0.081175 & -1.340503 & 0.180082 & -0.04031 & -0.03180 & -0.008628 \\
\hline $\mathrm{W}^{*} \operatorname{LnRD}$ & -0.422442 & -8.221621 & 0.000000 & -0.15045 & -0.15635 & -0.168242 \\
\hline $\mathrm{W}^{*} \mathrm{LnUR}$ & 0.351178 & 2.798591 & 0.005133 & 0.016906 & 0.102838 & 0.096679 \\
\hline $\mathrm{W}^{*} \mathrm{LnFDI}$ & -0.035159 & -0.855186 & 0.392448 & -0.11351 & -0.05758 & -0.029069 \\
\hline $\mathrm{W}^{*} \mathrm{LnIS}$ & 1.027140 & 5.893847 & 0.000000 & 0.561836 & 0.286806 & 0.503787 \\
\hline W*LnEI & 0.304976 & 3.733706 & 0.000189 & 0.359999 & 0.239992 & 0.320996 \\
\hline Model type & $\mathrm{R}^{2}$ & Adj- $R^{2}$ & loglikelihood & & & \\
\hline Random effect & 0.7390 & 0.7385 & -89.13373 & & & \\
\hline Spatial fixed effect & 0.9581 & 0.8392 & 539.8541 & & & \\
\hline Time fixed effect & 0.7862 & 0.7190 & -30.75541 & & & \\
\hline Spatiotemporal dual fixed effect & 0.9638 & 0.3401 & 586.03371 & & & \\
\hline
\end{tabular}

Note: $\mathrm{W}_{2}, \mathrm{~W}_{3}, \mathrm{~W}_{4}$ represent for the estimated results under the 0-1 matrix, the economic distance matrix, and the economic-geographic distance matrix respectively. 
Table 5. Decomposition results of spatial Durbin model.

\begin{tabular}{|c|c|c|c|c|}
\hline & Variable & Coefficient & t-statistic & p-value \\
\hline \multirow{6}{*}{ Direct effect } & $\mathrm{LnCV}$ & 0.030441 & 1.140974 & 0.262907 \\
\hline & LnCR & 0.041168 & 3.653665 & 0.000980 \\
\hline & LnRD & 0.058036 & 3.364581 & 0.002111 \\
\hline & LnUR & 0.129380 & 3.378254 & 0.002037 \\
\hline & LnFDI & -0.032348 & -3.760698 & 0.000734 \\
\hline & LnIS & 0.322330 & 7.204822 & 0.000000 \\
\hline \multirow{6}{*}{ Indirect effect } & $\mathrm{LnCV}$ & 0.298573 & 3.418930 & 0.001830 \\
\hline & LnCR & -0.092995 & -1.033331 & 0.309708 \\
\hline & LnRD & -0.576704 & -7.433454 & 0.000000 \\
\hline & LnUR & 0.560442 & 2.878600 & 0.007297 \\
\hline & LnFDI & -0.062818 & -1.034236 & 0.309292 \\
\hline & LnIS & 1.593352 & 6.786888 & 0.000000 \\
\hline \multirow{6}{*}{ Total effect } & $\mathrm{LnCV}$ & 0.329014 & 3.740903 & 0.000774 \\
\hline & $\mathrm{LnCR}$ & -0.051827 & -0.555451 & 0.582705 \\
\hline & LnRD & -0.518667 & -6.815951 & 0.000000 \\
\hline & LnUR & 0.689822 & 3.550271 & 0.001292 \\
\hline & LnFDI & -0.095167 & -1.506176 & 0.142480 \\
\hline & LnIS & 1.915683 & 8.030322 & 0.000000 \\
\hline
\end{tabular}

the model is decomposed into the direct effect and the indirect effect. The results are shown in Table 5.

\section{Results of the GWR Model and Classification of Provinces}

The data of 1995, 2002, 2010 and 2017 were selected to analyze the difference of influence factors of each province. Results of OLS estimation in each year show that the VIF of each factor is less than 8 , but the regression model established by ordinary panels will have spatial non-stationarity. Therefore, the geographically weighted regression estimation can be carried out due to the low degree collinearity of each factor. The overall estimation of each factor and difference test results are shown in Table 6. Through the results of t-test, most of coefficients have passed the significance test. The standard values are basically negative except for coefficient of foreign direct investment in 1995 and 2002, indicating that there is a large difference in factors among provinces.

It can be seen from the mean of each coefficient that the influence direction of each factor is similar to the result of spatial panel regression in general. But in 1995 and 2002, the influence direction of $R \& D$ expenditure and civil vehicles are opposite between maximum values and minimum values, which indicates that the positive and negative effects of the factor on various regions are different. Taking the coefficient estimation results of each influencing factor for different regions into the spatial distribution map, the results are shown in Fig. 4.

Fig. 4.1 shows that the influence coefficient of civil vehicles on the energy intensity of each region has not changed much in the four years of study. The coefficients are between 0.1 and 0.4 , and the gap between coefficients first increases and then decreases. The impact is basically positive, except that Xinjiang has a negative coefficient in 2002, the absolute value of which is so small that can be ignored. As is shown in Fig. 4.2, the impact of coal consumption proportion on the energy intensity of each region is positive with a decreasing trend. The coefficients in 1995 are above 0.7 , which was the main reason for the change in energy intensity. By 2017, coefficients of coal consumption proportion had basically reached below 0.2. From Fig. 4.3 , the negative impact of R\&D expenditure on energy intensity in various regions has gradually increased over the four years of the study. The results indicate that increasing the R\&D expenditure can effectively reduce energy intensity. Fig. 4.4 shows that the impact of urbanization rate on energy intensity is positive, and the coefficients of each region raise rapidly during the four years studied. The gap between provinces is also increasing. It can be seen from Figs. 4-5 that the impact of foreign direct investment on energy intensity is negative, and the coefficients tend to decrease during the four years of research. Except for the smaller 
Table 6. Estimated results of fitting indicators and influencing factor coefficients.

\begin{tabular}{|c|c|c|c|c|c|c|c|c|c|c|}
\hline Year & Statistic & Intercept & LNCV & LNCR & LNRD & LNUR & LNFDI & LNIS & \multicolumn{2}{|c|}{ Fit index } \\
\hline \multirow{4}{*}{1995} & Mean & -4.575 & 0.268 & 0.750 & -0.027 & 0.352 & -0.321 & 0.198 & $\mathrm{R}^{2}$ & 0.904 \\
\hline & Min & -4.971 & 0.182 & 0.755 & -0.043 & 0.252 & -0.338 & 0.113 & Adj-R ${ }^{2}$ & 0.860 \\
\hline & Max & -4.489 & 0.303 & 0.783 & 0.022 & 0.398 & -0.321 & 0.370 & $\mathrm{AICc}$ & -1.198 \\
\hline & $\begin{array}{c}\text { DIFF- } \\
\text { Criterion }\end{array}$ & -2.585 & -1.967 & -8.055 & -0.274 & -1.227 & 0.578 & -18.86 & $\begin{array}{l}\text { Band- } \\
\text { width }\end{array}$ & 21.25 \\
\hline \multirow{4}{*}{2002} & Mean & -5.563 & 0.164 & 0.306 & -0.025 & 0.603 & -0.333 & 0.698 & $\mathrm{R}^{2}$ & 0.803 \\
\hline & Min & -5.902 & -0.003 & 0.057 & -0.057 & 0.454 & -0.353 & 0.413 & Adj-R ${ }^{2}$ & 0.701 \\
\hline & Max & -5.229 & 0.228 & 0.524 & 0.028 & 0.698 & -0.299 & 1.157 & $\mathrm{AICc}$ & 21.366 \\
\hline & $\begin{array}{c}\text { DIFF- } \\
\text { Criterion }\end{array}$ & -30.248 & -2.080 & -3.018 & -2.422 & -0.636 & 0.751 & -13.07 & $\begin{array}{l}\text { Band- } \\
\text { width }\end{array}$ & 18.461 \\
\hline \multirow{4}{*}{2010} & Mean & -4.548 & 0.307 & 0.385 & -0.222 & 0.537 & -0.240 & 0.361 & $\mathrm{R}^{2}$ & 0.812 \\
\hline & Min & -5.156 & 0.105 & 0.087 & -0.332 & 0.405 & -0.286 & 0.064 & Adj-R ${ }^{2}$ & 0.695 \\
\hline & Max & -3.629 & 0.385 & 0.597 & -0.145 & 0.654 & -0.130 & 0.857 & $\mathrm{AICc}$ & 24.198 \\
\hline & $\begin{array}{c}\text { DIFF- } \\
\text { Criterion }\end{array}$ & -145.1 & -6.244 & -123.5 & -3.749 & -28.09 & -1.323 & -64.00 & $\begin{array}{l}\text { Band- } \\
\text { width }\end{array}$ & 13.898 \\
\hline \multirow{4}{*}{2017} & Mean & -2.750 & 0.265 & 0.137 & -0.280 & 0.486 & -0.126 & 0.160 & $\mathrm{R}^{2}$ & 0.707 \\
\hline & Min & -4.985 & 0.239 & 0.085 & -0.443 & 0.317 & -0.143 & 0.051 & $\operatorname{Adj}-R^{2}$ & 0.565 \\
\hline & Max & -1.640 & 0.363 & 0.209 & -0.234 & 0.884 & -0.093 & 0.434 & $\mathrm{AICc}$ & 37.251 \\
\hline & $\begin{array}{c}\text { DIFF- } \\
\text { Criterion }\end{array}$ & -97.998 & -1.168 & -0.598 & -5.387 & -32.77 & -0.236 & -12.24 & $\begin{array}{l}\text { Band- } \\
\text { width }\end{array}$ & 21.248 \\
\hline
\end{tabular}

influence of the northwest and northeast regions, the impacts of other regions are similar. As shown in Fig. 4.6, the impact of the of secondary industry proportion on energy intensity has been positive and significant, and the coefficients show a trend of first increasing and then decreasing in the four years of study.

According to the size of the influencing factors estimated by the GWR model, 30 provinces was classified in order to proposes specific suggestions for reducing energy intensity in various provinces. Taking the change of influence level in each year into account, the average impact level of different factors in the research year was analyzed. The provinces are ranked and divided into three levels: high, medium and low, considering the impact level of each factor. As shown in Fig. 5, 30 provinces were clustered according to the level of different influencing factors and finally divided into 7 categories.

The first category consists of six provinces, including Shanghai, Zhejiang, Fujian, Jiangsu, Guangdong, and Anhui, of which the coal consumption proportion is affected greatly. The urbanization rate was the key factor on the second category consisting of Neimenggu, Hebei, and Shanxi. The third category consists of five provinces, including Hubei, Hunan, Guangxi, Hainan and Jiangxi, and foreign direct investment has greater impact. The fourth category was Guizhou, Shaanxi, Sichuan, Yunnan and Chongqing. The influence of secondary industries proportion in these provinces is relatively large. The secondary industries proportion as well as R\&D expenditure has a large impact on the fifth category, including Xinjiang, Gansu, Ningxia and Qinghai. Civil vehicles of both the sixth and the seventh categories have a large influence on energy intensity. In addition, R\&D expenditure also plays an important role in the seventh category, including Heilongjiang, Beijing, and Jilin.

\section{Discussion}

\section{Analysis of Spatial Dubin Model Effect Decomposition}

The decomposition results of direct and indirect effects reflect the local and surrounding effects of factors. Civil vehicles have a positive effect on the energy intensity of both the local region and surrounding area. The indirect effects passed the significance test with the spillover influence coefficient at 0.298573 , but the direct effects impact is not obvious. The total effect of civil vehicles is positive, indicating that the increase in civil vehicles will increase the energy consumption and energy intensity, which proves the previous study that vehicles may be a key factor leading to corresponding energy consumption. Meanwhile, the increase of civil vehicles means the rise of resident consumption pulling up the local GDP, which makes insignificant effects and less range increase in energy intensity [36]. The GDP 


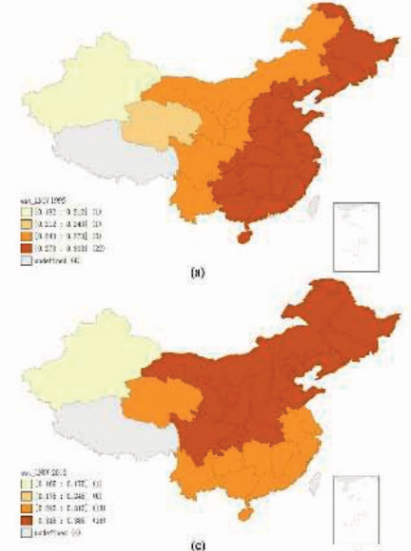

(1) $-\mathrm{CV}$

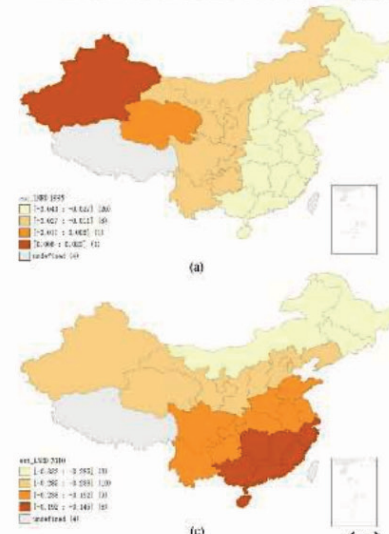

(3) $-\mathrm{R}$

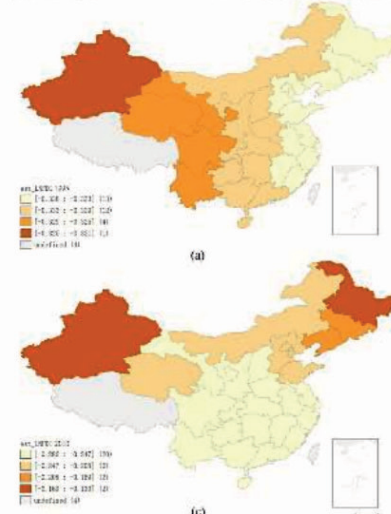

(5)-FDI
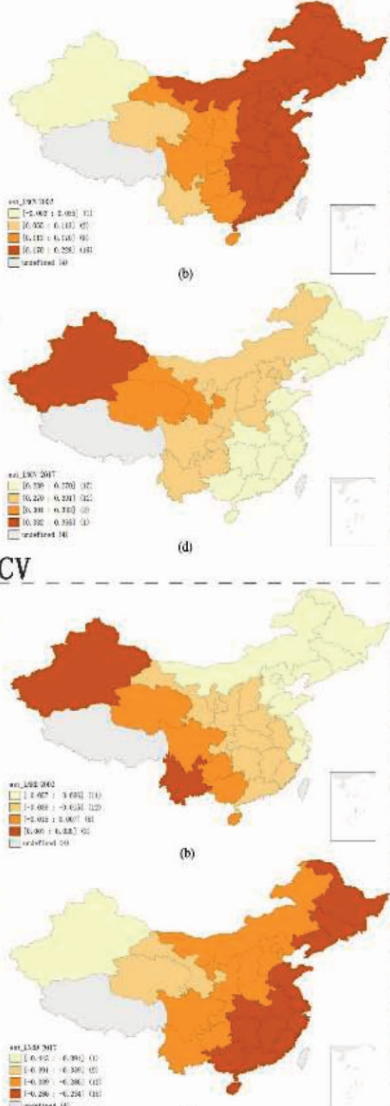

$-\mathrm{RD}$
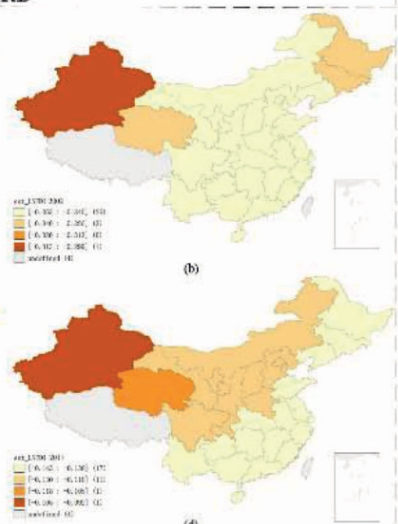

)

Fig. 4. Distribution map of influence coefficient.

may grow slightly lower than energy consumption of civil vehicles increases. By comparison, civil vehicles have little effect on surrounding economic development, thus the positive spillover effect of civil vehicles on the surrounding areas is more obvious.

The proportion of coal consumption has a significant effect on promoting energy intensity of the local region, the coefficient of which is 0.410168 . The result is similar to a previous study [37]. But the effect on the surrounding area is negative and insignificant. On the whole, the total effect of coal consumption proportion is slightly negative, and its impact is not significant. As the calorific value of coal is low, coal needs to consume more compared with clean energy such as natural gas.

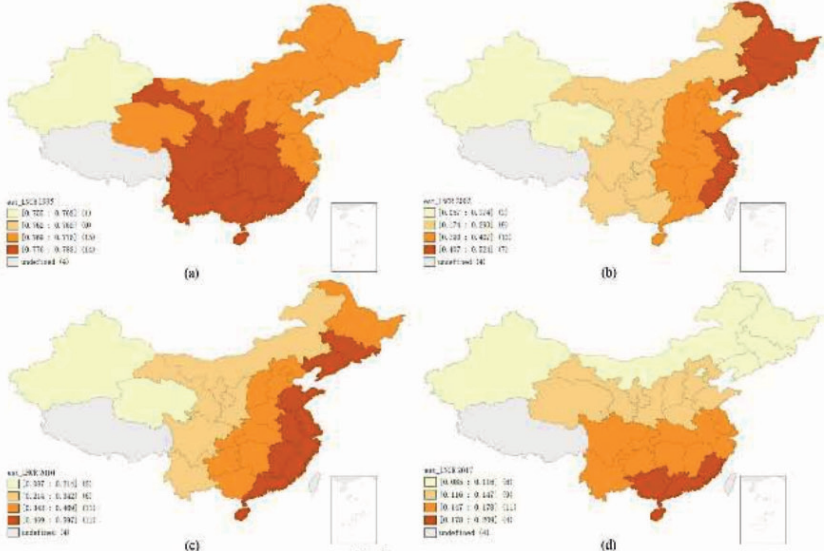

(2) $-\mathrm{CR}$

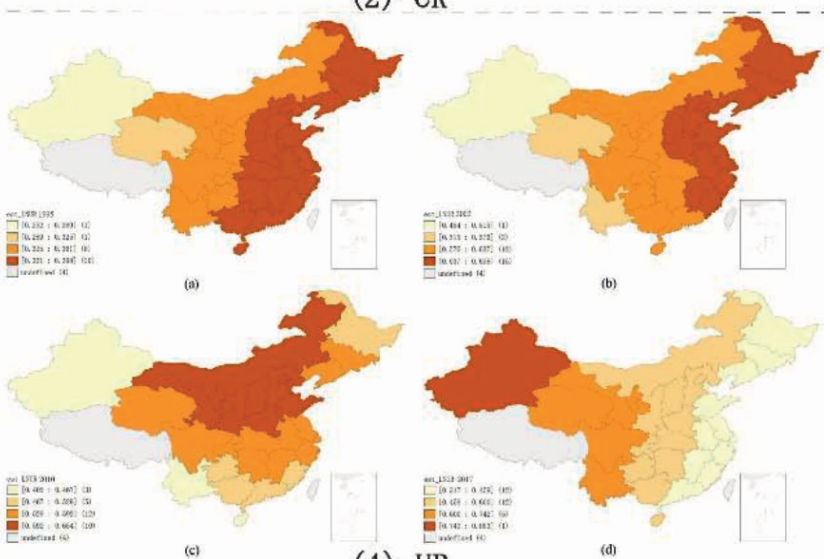

(4) $-\mathrm{UR}$

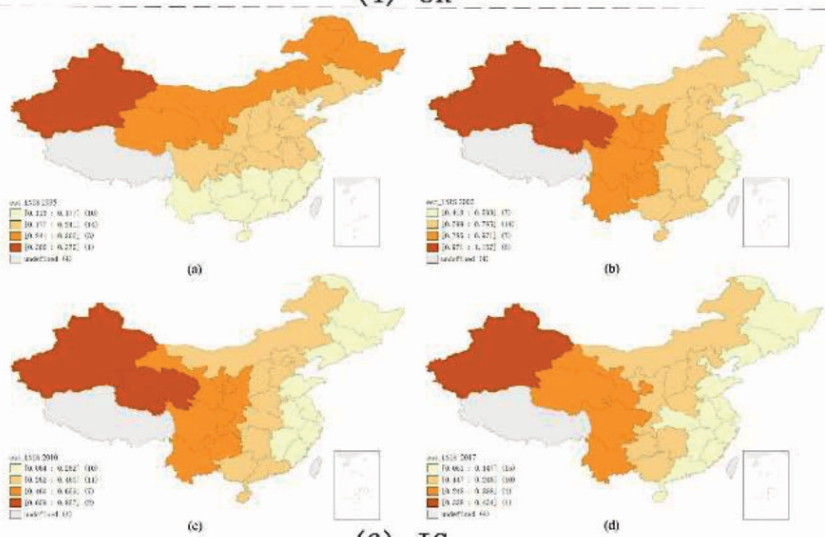

(6) - IS

Therefore, the increase in coal consumption will raise the energy intensity, though the surrounding areas are only slightly affected by coal consumption changes in the local region. Coal is mainly concentrated in the northern region of China, and it is difficult to obtain coal from the neighboring areas in the southern coaldeficient areas. Therefore, the coal consumption proportion of the local cannot drive coal consumption in the surrounding areas, which leads to an insignificant impact.

There is a significant effect of R\&D expenditure on both local and surrounding areas. The local effect is positive, opposite to the surroundings. The total effect of R\&D expenditure is considered significantly 


\section{Cluster Dendrogram}

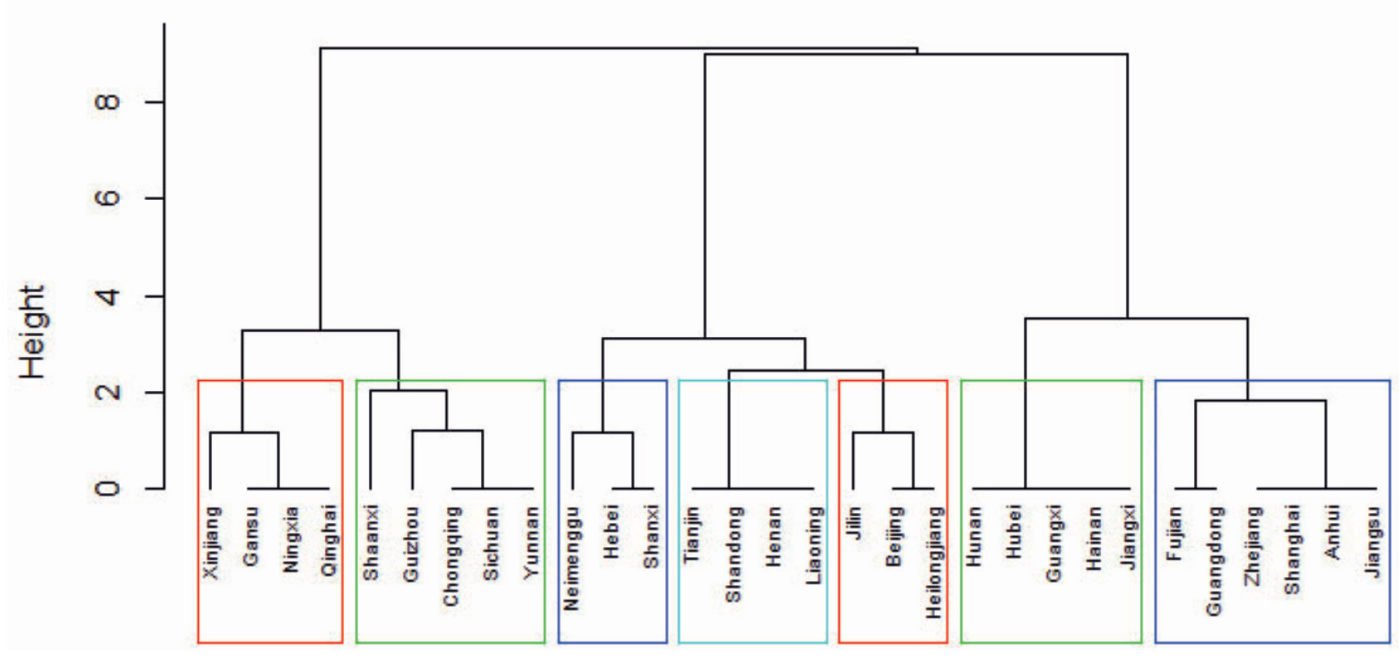

Fig. 5. Clustering results of influencing factor rankings.

negative, reaching 0.518667 . The results correspond to the conclusion of Dong et al. that $R \& D$ expenditure is the main driver of energy intensity reduction [38]. The increase in internal $\mathrm{R} \& \mathrm{D}$ expenditure has led to the development of technology that has improve energy efficiency and overall reduced energy intensity in local and surrounding areas while developing the economy. However, the increase in technology has enabled more energy-intensive companies expanding production scale. Rapid development of secondary industry, especially the heavy metal industry, has expanded energy consumption for the local region. Thus the energy intensity of the local region has been driven up to a certain extent, which was somewhat different from a previous study [39].

Foreign direct investment has an inhibitory negative effect on energy intensity in the local region and surrounding area. The coefficient of effect on local energy intensity is 0.032348 , showing that the influence is significant. But the effect on energy intensity in surrounding areas is not obvious. Foreign investment expands the degree of regional opening up as well as improves the level of energy utilization technology [40]. In the early stage of foreign investment, local enterprises have just begun to develop, and it is difficult to form a scale effect with the surrounding areas, so FDI has not promoted the development of the surrounding areas. Therefore, the development of lowenergy industries such as the financial industry reduce energy intensity, but had little impact on the spillover of surrounding areas.

Urbanization rate and secondary industry proportion have significant positive effects on the energy intensity of the local region and the surrounding areas, with total effect coefficients of 0.689822 and 1.915683 respectively. The improvement of urbanization brings a large population and direct demand for resources. At the same time, the expansion of the scale of secondary industries such as industry requires more electricity and fuel, and the consumption of energy is increasing rapidly. However, the role of economic growth brought by urbanization is at a preliminary stage, and the secondary industry economic growth is slowing down. The result has proved the previous study that these factors make the energy intensity increase [41].

\section{Differentiation Analysis of Influence Factor Coefficient}

Areas with high influence of civil vehicles have changed from southeast to northeast, then gradually from north to northwest, showing a general counterclockwise trend that is related to traffic development in China. As the eastern region has a high population density, the demand for transportation is large, which required many oil products, leading to a greater impact on the energy intensity of the region. With economic development, civil vehicles spread to the western and northern parts, and the high-impact areas have gradually expanded [42]. In recent years, new energy vehicles began to be encouraged and promoted by various regions. The energy-saving effect of new energy vehicle applications in the eastern region was manifested, and the impact of civil vehicles on energy intensity has decreased. The promotion of new energy vehicles in the central region was not strong enough and the charging infrastructure of new energy vehicles and road construction is imperfect, so the impact is basically the same during study periods. Civil vehicles have increased in the western region, and the majority of the vehicles is mostly fuel-efficient, bringing about the enhanced impact on energy consumption [43]. Therefore, the impact of civil vehicles on energy intensity continues to increase - especially in the northwest. 
The areas with a high level of coal consumption impact are gradually shrinking, mainly in the eastern and southern regions. As a big country in coal consumption, China's coal utilization efficiency is low in the early stage, and unit consumption is large. The reduction of coal consumption proportion can effectively reduce energy intensity. With the development of clean coal technology and the widespread use of clean energy, the coal trade between different regions becomes cleaner. Centralized heating and other measures adopted in the northern region have effectively reduced the impact of coal as previous studies [44]. But it is still at a high level in the eastern and southern areas, where coal resources are scarce. The impact of coal consumption on these areas is related to supply and demand market and coal prices. The coal demand in coastal areas has maintained a growth trend opposite coal output, making the impact of coal higher than that in the north.

The influence coefficient of R\&D expenditure in the western region changes more than that in the eastern region. The results in 1995 and 2002 that Xinjiang and Qinghai have positive coefficient contrary to other regions indicate that these provinces are more inclined to invest in new technologies in high-energy-consuming industries that can rapidly develop the economy, and energy intensity is consequently enhanced. At this time, although the energy intensity in the eastern region declined by $\mathrm{R} \& \mathrm{D}$ expenditure, competition exists in the output of science technology and highquality talents in different regions, the impact is not significant due to the low level of technology [45]. In 2010 and 2017, the influence of R\&D expenditure in various regions increased rapidly, and gradually became the main factor affecting energy intensity. Each region promotes the development of innovative industries by driving technology mutually. More attention was paid to energy-saving technology in different regions, and the cumulative technology has an increasing effect on improving energy efficiency. The results prove the previous study that $R \& D$ experiment plays a more important role in the development stage than in the basic stage [46].

Areas with high levels of urbanization have gradually turned counterclockwise from the southeast to the northwest. In the early years of the study, the urbanization level of the eastern region developed rapidly, bringing about a substantially increased population. The improvement of living standard consumes a lot of energy in transportation and electricity. But the population outflow in the western region with low, level of infrastructure construction. Therefore, the impact of urbanization on the eastern region is even greater. With the development policy of the western region, urbanization of western regions come to an initial stage, the construction of energyintensive infrastructure and the increase of traffic demand in the process of urbanization make energy intensity increase during four research years [47]. However, urbanization in the eastern region has reached a certain high level and started to stabilize, so the influence coefficient of urbanization rate in the eastern region remains basically unchanged.

The gaps in foreign direct investment between provinces are relatively small. In the early stage of research, foreign investment brought opportunities for rapid economic development, such as improvement of production and management technology as well as advanced equipment, which has a greater impact on the reduction of energy intensity. With the enhancement of economic strength and the increase of domestic investment level, the economic effect of foreign investment is relatively weak. The impact of foreign direct investment on energy intensity began to decrease, but the impact gap has slightly increased in each year. Due to the emphasis on environment and energy in the eastern and central regions, foreign investors have gradually turned to low-energy tertiary industry investment, but there are still many foreign-invested enterprises with high energy-consuming industries in the northwest region, which has increased energy consumption [48].

The influence of the secondary industry proportion in different regions is quite different, performing higher in the northern than southern regions, and the western region is higher than the eastern region. In the early stage of research, China's industrialization level is not high, with less industrial energy consumption. The influence coefficient of provinces is small, and the gap is not big. In 2002, the scale of heavy industry was expanding rapidly for the rapid development of the economy. Many industrial enterprises and infrastructure investments have brought about energy consumption, but also a large amount of energy waste [49]. The impact of the secondary industry proportion on energy intensity became greater, especially in the western region, with an impact coefficient greater than one. In the later stage of the study, with the regulation and restrictions on high-energy-consuming industries, the impact of the proportion of secondary industry on energy intensity decreased. The industrial transfer between the east and the west makes the coefficient of the eastern region decrease earlier and faster.

\section{Conclusions and Policy}

Using panel data from 1995 to 2017, this paper applies the spatial Durbin and GWR models to explore the different main factors affecting energy intensity in the 30 provinces. The main conclusions are as follows. According to the coefficients and spillover coefficients of 6 influence factors, urbanization rate and secondary industry proportion has a significant positive influence on both local and surrounding areas, while civil vehicles are only positive on the surroundings. The proportion of coal consumption and foreign direct investment have the opposite effect on location, while R\&D expenditure has a different influence on local and surrounding areas. 
Then the coefficients of 30 provinces were considered be highly differentiated through the spatial distribution map, and the impact of 6 factors changed in different research years. In addition, 30 provinces were divided into 7 groups with various key impacts.

Based on the above empirical results, each province should adapt to local conditions and grasp the key factors affecting energy intensity. Therefore, this paper puts forward corresponding policy countermeasures.

(1) Government of the $4^{\text {th }}$ and $5^{\text {th }}$ group provinces should control energy consumption of the secondary industry while increasing investment to improve the energy-saving level in industry. They can formulate corresponding incentive policies to encourage industries with high energy consumption such as industry and transportation to use clean energy, and transform the focus of development from energy-consuming industries to businesses of resource saving. The existing industries should accelerate greening with high-tech materials and equipment in order to reduce the necessary energy consumption in industrial development. Besides, it is important to accelerate economic transition and promote industrial upgrading, forming an overall development style of the third industry.

(2) Provinces in the $2^{\text {th }}$ group should optimize the spatial location of residential and commercial areas so as to make the population more centralized. It is necessary to focus on urban layout and improve the agglomeration effect of urbanization while the level of urbanization is constantly developing. Concentrated energy supply reduces transport losses and consumption of resident accommodation and transportation, decreasing the impact of the population increase brought about by urbanization on overall energy consumption. The government would be better off formulating the guiding policy and promoting energy-saving ways to improve living standards, turning environmental protection concepts into habits.

(3) Provinces like the $3^{\text {th }}$ and $7^{\text {th }}$ group should pay attention to coordinating the relationship between economic development and the environment, and guiding investment in developing cleaner energy, thereby improving the local energy-saving level. Local governments can provide some start-up funds to attract high-tech industries, formulating corresponding incentive preferential policies to enable enterprises to innovate independently. The focus of government investment and foreign investment will gradually shift from large-scale energy industries to an innovative enterprise, exerting the role of technology in urban energy-saving development.

(4) The $1^{\text {th }}$ and $6^{\text {th }}$ group of provinces could make policies to expand the coverage of clean energy. The proportions of clean energy like wind power, nuclear power and hydropower in primary energy consumption should be increased. The government set a long-term development policy like increasing the regulation of taxes and fees in the coal industry. It is useful to rationally expand investment in clean energy utilization and improve energy utilization infrastructure. On the one hand, these provinces encourage enterprises to expand the production and sales of clean energy vehicles. On the other hand, it is available to formulate a certain subsidy policy to reduce prices to encourage residents to purchase. At the same time, the government should restrict the use of energy-consuming vehicles and control the passenger population. From the perspective of residents, expanding the recycling of renewable energy will optimize the energy structure on the residential side.

\section{Acknowledgements}

This paper was supported by the Social Science Foundation of Beijing (project ID 15JGB050).

\section{Conflict of Interest}

The authors declare no conflict of interest.

\section{References}

1. LIN J., FRIDLEY D., LU H.Y., PRICE L., ZHOU N. Has coal use peaked in China: Near-term trends in China's coal consumption. Energy Policy. 123, 208, 2018.

2. YU H. The influential factors of China's regional energy intensity and its spatial linkages: 1988-2007. Energy Policy. 45, 583, 2012.

3. WU J.X., WU Y.R., CHENG T.S., YU Y.N. Distribution dynamics of energy intensity in Chinese cities. Applied Energy. 211 (1), 875, 2018.

4. GANDHI O., OSHIRO A.H., MEDEIROS COSTA H.K., Santos E.M. Energy intensity trend explained for Sao Paulo state. Renewable and Sustainable Energy Reviews. 77, 1046, 2017.

5. WANG J.M., YANG F., ZHANG X.T. Analysis of the Influence Mechanism of Energy-Related Carbon Emissions with a Novel Hybrid Support Vector Machine Algorithm in Hebei, China. Pol. J. Environ. Stud. 28 (5), 3475, 2019.

6. LI Y.M., SUN L.Y., ZHANG H.L., LIU T.T., FANG K. Does industrial transfer within urban agglomerations promote dual control of total energy consumption and energy intensity? Journal of Cleaner Production. 204 (10), 607, 2018.

7. LAM K.L., KENWAY S.J., LANE J.L., NAZMUL ISLAM K.M., BERC R.B. Energy intensity and embodied energy flow in Australia: An input-output analysis. Journal of Cleaner Production. 226 (20), 357, 2019.

8. ZHANG P., WANG X., ZHANG N., WANG Y.Y. China's energy intensity target allocation needs improvement! Lessons from the convergence analysis of energy intensity across Chinese Provinces. Journal of Cleaner Production. 223 (20), 610, 2019.

9. ZHANG P. Do energy intensity targets matter for wind energy development? Identifying their heterogeneous effects in Chinese provinces with different wind resources. Renewable Energy. 139, 968, 2019.

10. NAHLA S. Energy intensity and its determinants in OPEC countries. Energy, 186, 115803, 2019. 
11. YANG G.F., LI W.L., WANG J.L., ZHANG D.Q. A comparative study on the influential factors of China's provincial energy intensity. Energy Policy. 88, 74, 2016.

12. DONG K.Y., SUN R.J., HOCHMAN G., LI H. Energy intensity and energy conservation potential in China: A regional comparison perspective. Energy. 155 (15), 782, 2018.

13. SONI A., MITTAL A., KAPSHE M. Energy Intensity analysis of Indian manufacturing industries. ResourceEfficient Technologies. 3 (3), 353, 2017.

14. PETROVIC P., FILIPOVIC S., RADOVANOVIC M. Underlying causal factors of the European Union energy intensity: Econometric evidence. Renewable and Sustainable Energy Reviews. 89, 216, 2018

15. TAN R.P., LIN B.Q. What factors lead to the decline of energy intensity in China's energy intensive industries? Energy Economics. 71, 213, 2018.

16. BU M.L., LI S., JIANG L. Foreign direct investment and energy intensity in China: Firm-level evidence. Energy Economics. 80, 366, 2019.

17. JIANG L., FOLMER H., JI M.H., Zhou P. Revisiting cross-province energy intensity convergence in China: A spatial panel analysis. Energy Policy. 121, 252, 2018.

18. ZHAO X.G., ZHANG Y.F., LI Y.B. The spillovers of foreign direct investment and the convergence of energy intensity. Journal of Cleaner Production. 206 (1), 611, 2019.

19. HUANG J.B., HAO Y., LEI H.Y. Indigenous versus foreign innovation and energy intensity in China. Renewable and Sustainable Energy Reviews. 81 (2), 1721, 2018.

20. CHEN C.H., HUANG J.B., CHANG H.G., LEI H.Y. The effects of indigenous R\&D activities on China's energy intensity: A regional perspective. Science of The Total Environment. 689 (1), 1066, 2019.

21. TANG D.L., XU H., YANG Y.H. Mutual Influence of Energy Consumption and Foreign Direct Investment on Haze Pollution in China: a Spatial Econometric Approach. Pol. J. Environ. Stud. 27(4), 1743, 2018

22. KARIMU A., BRANNLUND R., LUNDGREN T., SODERHOLM P. Energy intensity and convergence in Swedish industry: A combined econometric and decomposition analysis. Energy Economics. 62, 347, 2017.

23. VERBIC M., FILIPOVIC S., RADOVANOVIC M. Electricity prices and energy intensity in Europe. Utilities Policy. 47, 58, 2017.

24. GUO X.D, XIAO B., SONG L. What cause the decline of energy intensity in China's cities? A comprehensive panel-data analysis. Journal of Cleaner Production. 233, 1298, 2019.

25. NIRLSEN H., WARDE P., KANDER A. East versus West: Energy intensity in coal-rich Europe, 1800-2000. Energy Policy. 122, 75, 2018.

26. LIN B.Q., CHEN Y. Will economic infrastructure development affect the energy intensity of China's manufacturing industry? Energy Policy. 132, 122, 2019.

27. GUANG F.T., HE Y.X., WEN L., SHARP B. Energy intensity and its differences across China's regions: Combining econometric and decomposition analysis. Energy. 180 (1), 989, 2019.

28. WANG Y.N., LI X.B., KANG Y.Q., CHEN W., LI W. Analyzing the impact of urbanization quality on $\mathrm{CO}_{2}$ emissions: What can geographically weighted regression tell us? Renewable and Sustainable Energy Reviews. 104, 127, 2019.

29. QIN H.T., HUANG Q.H., ZHANG Z.W., LU Y., CHEN Z.J. Carbon dioxide emission driving factors analysis and policy implications of Chinese cities: Combining geographically weighted regression with two-step cluster. Science of The Total Environment. 684 (20), 413, 2019.

30. ANSELIN L. Local indicators of spatial associationLISA. Geographical Analysis. 27, 93, 1995

31. NAMINSE E.Y., ZHUANG J.C. Economic Growth, Energy Intensity, and Carbon Dioxide Emissions in China. Pol. J. Environ. Stud. 27 (5), 2193, 2018.

32. LANG W., LONG Y., Chen T.T., LI X. Reinvestigating China's urbanization through the lens of allometric scaling. Physica A: Statistical Mechanics and its Applications. 525 (1), 1429, 2019.

33. TIENTAO A., LEGROS D., PICHERY M.C. Technology spillover and TFP growth: A spatial Durbin model. International Economics. 145, 21, 2016.

34. ANSELIN L. Spatial Econometrics: Methods and Models. Springer Science \& Business Media. 2013.

35. FOTHERINGHAM A.S. Spatial variations in school performance: a local analysis using geographically weighted regression. Geographical and Environmental Modelling. 5, 43, 2001.

36. FADIRAN G., ADEBUSUYI A.T., FADIRAN D. Natural gas consumption and economic growth: Evidence from selected natural gas vehicle markets in Europe. Energy. 169 (15) 467, 2019.

37. LI H.Z., SAVOLAINEN M.K., YAN M.Z., WANG J.L., XIE C.B. Which provincial administrative regions in China should reduce their coal consumption? An environmental energy input requirement function based analysis. Energy Policy. 127, 51, 2019.

38. PAN X.F., UDDIN M.K., HAN C.C., PAN X.Y. Dynamics of financial development, trade openness, technological innovation and energy intensity: Evidence from Bangladesh. Energy. 171 (15), 456, 2019.

39. ZHENG Y.M., QI J.H., CHEN X.L. The effect of increasing exports on industrial energy intensity in China. Energy Policy. 39 (5), 2688, 2011.

40. LI C.C., TANNA S. The impact of foreign direct investment on productivity: New evidence for developing countries. Economic Modelling. 80, 453, 2019.

41. YANG Y.C., LIU J.H., LIN Y.Y., LI Q.Y. The impact of urbanization on China's residential energy consumption. Structural Change and Economic Dynamics. 49, 170, 2019.

42. QIAO Q.Y., ZHAO F.Q., LIU Z.W., HAO H. Electric vehicle recycling in China: Economic and environmental benefits. Resources, Conservation and Recycling. 140, 45, 2019.

43. DU Z.L., LIN B.Q., GUAN C.X. Development path of electric vehicles in China under environmental and energy security constraints. Resources, Conservation and Recycling. 143, 17, 2019.

44. DZIKUC M., KULYK P., DZIKUC M., STANISLAW U., ARKADIUSZ P. Outline of Ecological and Economic Problems Associated with Low Emission Reductions in Poland's Lubuskie Voivodeship. Pol. J. Environ. Stud. 28 (1), 65, 2019.

45. LI W., ZHANG H.Z., ZHANG S. The Impact of Energy De-Subsidization Policy in 2030: A Dynamic CGE Model in China. Pol. J. Environ. Stud. 28 (4), 2187, 2019

46. LI P.H., JONES S. Vehicle restrictions and $\mathrm{CO}_{2}$ emissions in Beijing-A simple projection using available data. Transportation Research Part D: Transport and Environment. 41, 467, 2015.

47. YAN H.J. Provincial energy intensity in China: The role of urbanization. Energy Policy. 86, 635, 2015. 
48. LI W., ZHAO T., WANG Y.N., ZHENG X.D., YANG J.X. How does foreign direct investment influence energy intensity convergence in China? Evidence from prefecturelevel data. Journal of Cleaner Production. 219 (10), 57, 2019.
49. SHEN N., DENG R.M., WANG Q.W. Influence of Agglomeration of Manufacturing and the Producer Service Sector on Energy Efficiency. Pol. J. Environ. Stud. 28 (5), 3401, 2019. 